\title{
COVID-19 and Fertility in Canada: a Commentary
}

\section{Ana Fostik ${ }^{1}$}

Received: 3 August 2021 / Accepted: 9 August 2021 / Published online: 3 September 2021

(c) Crown 2021

The pandemic of the new coronavirus (COVID-19) constitutes not only a sanitary emergency, but also an unprecedented social and economic crisis. It has brought about increased levels of unemployment, an economic downturn, and amplified uncertainty about the future. Demographers are thus monitoring how family dynamics may change in response to the crisis, as the deterioration of economic conditions, labour market uncertainty, general societal uncertainty, and negative expectations about the future have all been associated with delays in childbearing (Alderotti et al., 2019; Boberg-Fazlić et al., 2017; Comolli \& Vignoli, 2021; Lappegård et al., 2021; Marteleto et al., 2020; Matysiak et al., 2020; Sobotka et al., 2011; Vignoli et al., 2020). Thus, reductions of the total fertility rate can be expected in Canada and other developed nations, at least in the short term (Aassve, et al. 2020). In addition, as a consequence of fertility postponement, mean age at first birth in Canada has been increasing over the past decades, reaching 29.4 years in 2019 (Statistics Canada, 2020a), making Canada a "late-late fertility" country, which exhibited a record low fertility rate of 1.47 children per woman in 2019 (Statistics Canada, 2020a). In this context, any delays in childbearing due to the COVID-19 pandemic, particularly among older women, could have a negative effect not only on period fertility rates but also on cohort-completed fertility.

\section{How Does Labour Market Uncertainty Affect Fertility at the Individual Level?}

Increased unemployment and the deterioration of labour market conditions are one of the main reasons why the COVID-19 crisis could impact fertility intentions and behaviour. After reaching a record high of 13.7\% in May 2020 (Statistics Canada, 2020b), and remaining above $9 \%$ between March and December 2020, the unemployment rate has decreased in 2021 (Statistics Canada, 2021b). However, the unemployment rate has remained higher than its pre-pandemic level, at $7.8 \%$, in June 2021 (Statistics Canada, 2021b). The employment rate and self-employment

Ana Fostik

ana.fostik@canada.ca

1 Statistics Canada, Ottawa, Canada 
also increased since March 2020 but remained below pre-pandemic levels by June 2021, whereas the underutilization rate remained higher, an indication that more people than before the start of the pandemic are working less than half their usual hours, searching for a job, in temporary lay-offs, or wanting to be employed but not finding a job (Statistics Canada, 2021b). All these indicators point to increased labour market uncertainty and precariousness, which have been negatively linked to fertility behaviour.

Before the pandemic, a meta-analysis of the impacts of unemployment and temporary employment on fertility in Europe showed that individuals who experienced episodes of unemployment tended to delay births (Alderotti et al., 2019), consistently with the fact that unemployment results in a loss of income and increased uncertainty about future job prospects. This was particularly true of male unemployment and affected births of all ranks (the first birth and subsequent ones). Furthermore, the study showed that the impact of unemployment episodes on fertility became more negative throughout the period from 1970 to 2015 .

On the other hand, women in some countries took advantage of periods of unemployment as a time to carry out their fertility plans and have children in that moment, as time for childbearing and childrearing became more available and the opportunity costs diminished. However, this was not true in the countries hardest hit by the 2008 Great Recession in Southern Europe such as Italy or Spain, which were also those with the lowest fertility rates.

Having a temporary job was also found to be negatively associated with childbearing, particularly among women and for second and subsequent births, which was interpreted to be due to the added financial burden of expanding the family. Among men, having a temporary job had less of an impact on births, which was interpreted in the context of the male breadwinner model: to start or expand a family, having a job, regardless of its characteristics, is better than having none.

The evidence for Canada only refers to high income, dual earner families (research hasn't covered educational attainment mainly those with higher educational levels and higher income (Marshall, Burd, \& Burrows, 2021). In Canada, teleworking was more prevalent in high income, two-earner families (Statistics Canada, 2021c). This greater compatibility between professional careers and childrearing could partially offset the negative impact of labour market uncertainty on fertility, at least among the groups which most benefited from the advantages of teleworking.

\section{The Effects of Economic Downturns on Fertility Rates}

Economic crises, as they translate into a reduction in GDP growth and an increase in unemployment, can impact fertility intentions and fertility behaviour even when individuals are not personally affected by the loss of a job or income. In times of uncertainty about the economic future and the stability of the labour market, individuals might become risk averse and avoid any long-term commitments, of which having a child is the most irreversible one. Negative expectations about the future may lead many families to postpone childbearing plans until times of greater certainty (Sobotka et al., 2011). 
Evidence for some subnational regions of the USA and Germany point to a decrease in fertility rates during the 1929 Great Depression (Kluesener \& Lerch, 2020). More recent examples of declines in fertility following a recession can be found in Europe and in the USA during and after the Great Recession of 2008-2009. Fertility rates decreased and then stagnated in most European regions, particularly those most affected by the recession, reversing in some cases the trends observed the first years of the 2000s towards increasing fertility. Matysiak et al. (2020) recently explored the impact of this recession on fertility in 28 European countries, focusing on the impact of unemployment, long-term unemployment, and GDP decline on fertility at the aggregate level. Unemployment increases had a significant effect, decreasing fertility rates. Moreover, the effect was even more negative during the period of the recession than before its start, suggesting that the impact of unemployment on fertility behaviour may be magnified during times of recessions (Matysiak et al., 2020).

\section{The Role of Fundamental Uncertainty}

While the European economy recovered after the recession, in many countries, fertility did not. This is especially true of some Nordic countries, where the effects of the Great Recession were mild and where fertility decline continued after 2014, when the macroeconomic conditions improved. This led some researchers to focus on the presence of "fundamental uncertainty" regarding the future and its impact on childbearing behaviour. Their argument is that fundamental uncertainty regarding the future of the economy, but also of politic systems at a global level, can enter the narratives of individuals regardless of their experiences in the labour market. As "narratives of uncertainty" become widespread, births are delayed, even when the economy is going well (Comolli \& Vignoli, 2021; Lappegård et al., 2020; Vignoli et al., 2020).

A study of the effects of a financial crisis in Italy in 2011-2012 showed an association between increased googling of the financial term "spread" (an indicator of the lack of confidence in the financial system) and a sharp decline in births 9 months after. The estimated reduction in lagged births as a consequence of these "narratives of uncertainty" was between 2.5 and 5\% (Comolli \& Vignoli, 2021).

\section{Observed Effects of COVID-19 on Fertility}

Evidence for several European countries shows that fertility plans were indeed revised during the early days of the COVID-19 pandemic, as very large proportions of the younger population-under 34 years old-reported delaying or abandoning their conceiving projects they had previously planned up to February 2020 in Italy, Germany, France, Spain, and the UK (Luppi et al., 2020). Fertility plans also changed among women in the USA during the pandemic; a survey conducted by the Guttmacher Institute found that about a third (34\%) of women reported wanting later births or fewer children because of the pandemic (Lindberg et al., 2020). These 
proportions were higher among non-Hispanic Black and Hispanic groups, among LGBTQ + women, and among those with low household income.

There is also recent evidence for developed countries that monthly birth rates declined in several national contexts starting in November 2020, compared to the same month of the preceding year (Sobotka et al., 2021). In the USA, births in December 2020 dropped by $8 \%$, whereas in 15 countries of the European Union, births declined on average by $3 \%$ in October $2020,5 \%$ in November 2020, and $8 \%$ in December 2020. In some countries, such as Spain, the declines were more dramatic, with births falling by $20 \%$ in December 2020 and January 2021. However, in other European countries such as Denmark, Finland, the Netherlands, and Norway, no changes to previous trends in monthly birth rates were observed for December 2020 and January 2021 (Sobotka et al., 2021). Evidence at the county-level for the USA shows an overall annual decline in births in 2020 of $3.8 \%$, where reductions in births were observed throughout the country, and steeper declines were detected in counties with higher prevalence of COVID-19 infections and in counties where mobility diminished the most (Cohen, 2021).

Little is yet known for Canada regarding possible changes in fertility intentions or behaviour associated with the COVID-19 pandemic. Some preliminary data for British Columbia shows that births reported in December 2020 declined by $6.9 \%$ compared with the same month in the preceding year (BC Vital Statistics Agency, $2021 \mathrm{a}, \mathrm{b}$ ), as well as a decline of $4.9 \%$ in births reported in January 2021 compared with the same month in 2020 (BC Vital Statistics Agency, 2021b, c). ${ }^{1}$ However, such declines are not observed after January 2021: births increased in March (3.7\%) and May (5.8\%). A decrease of over $2 \%$ in the year-over-year monthly births also occurred between May and October of 2020. This could be explained by the impact of COVID-19 on border closures, refraining pregnant new immigrants and non-permanent residents from landing in Canada. Combined with an already declining fertility, that could have caused a higher than usual decrease in births in 2020 in British Columbia.

In Quebec, reported annual births observed in 2020 declined by 3\% compared with annual births for $2019^{2}$ (Institut de la Statistique du Québec, 2021a). The province's fertility rate also fell from 1.57 in 2019 to 1.52 in 2020 (Institut de la Statistique du Québec, 2021b), with declines mainly occurring in the second portion of 2020 (Statistics Canada, 2021a). ${ }^{3}$ Also, Quebec vital statistics provided to Statistics Canada for the population estimates ${ }^{4}$ show that births for the first quarter of

\footnotetext{
1 Author's calculations based on BC Vital Statistics Agency "Births by Local Health Area" reports for 2019, 2020 and 2021.

2 Author's calculations based on the report "Naissances, décès, accroissement naturel et mariages par MRC, Québec, 2002-2020”, Institut National de la Statistique, 2021.

3 Author's calculations based on "Estimates of the components of natural increase, quarterly", Statistics Canada, 2021a.

${ }^{4}$ Quebec and British Columbia are the only two provinces to provide their own vital statistics data every quarter.
} 
2021 were $2.7 \%$ lower compared to the same quarter a year ago (Statistics Canada, 2021a). ${ }^{5}$ With the exception of Yukon, no data from vital statistics is yet available for the other Canadian provinces and territories.

A mediating variable to changes in fertility behaviour is possible changes in family formation and dissolution dynamics during the pandemic. Although it is still too early to tell whether the pandemic might have had an effect on union dissolution, there are some indicators that union formation might have been delayed in 2020, at least concerning marriages. Data for Quebec shows that marriages halved between 2019 and 2020 in the province; whereas 22,284 marriages were observed in 2019, and only 11,306 were registered in 2020 (Institut de la Statistique du Québec, 2021a). The impact of such a reduction in marriage could have been offset by childbearing in common-law unions.

\section{Recuperation of Fertility in the Medium and Long Term}

Experiences from past economic and sanitary crises have shown that a proportion of the births that are postponed in times of upheaval are caught up with later on (Boberg-Fazlić et al., 2017; Kluessener \& Lerch, 2020). Individuals might wait until times are less uncertain before going forward with births that were already planned. The total fertility rate is a snapshot indicator, which reflects how many children women would have on average, over their lifetime, if fertility conditions at the time of observation persisted during their entire reproductive life. That is why we can expect a reduction of fertility rates during a period of crisis, followed by an uptick once the crisis is over: births that were postponed can be "caught up" with, if reproductive plans and ideals remain intact, provided there is enough fecund time left.

However, it is possible that a part of these "missed" births might not materialise. In the context of the second demographic transition, in many Western countries, including Canada, births were postponed even before the pandemic, as women develop their professional and educational paths before entering motherhood. Even births at age 40 and older have increased in the past few decades, representing an increasing share of first births (Beaujouan, 2020). In 2014, it was estimated that $3.6 \%$ of all births in Canada were to mothers aged 40 and older (Beaujouan \& Sobotka, 2019). However, at age 40 and older, an important proportion of births are the result of assisted reproductive technology (Beaujouan, 2020); the use of such technology has been impacted by clinics closures and other restrictions during the pandemic.

Only time will tell if the generations impacted by the COVID-19 crisis will have the same number of children they were planning to have, but at a later time, or if their ideal number of children changed in these circumstances. If some adults decided to forego childbearing altogether as a response to the new challenges brought about by the pandemic and its associated economic crisis, younger generations might be more

\footnotetext{
5 Author's calculations based on "Estimates of the components of natural increase, quarterly", Statistics Canada, 2021a.
} 
likely to remain childless. Research about changes in fertility intentions before and after the pandemic will be of crucial importance to understand this key aspect of childbearing dynamics.

In this context, Statistics Canada is conducting a new survey, the Canadian Social Survey $\left(\mathrm{CSS}^{6}\right)$, which collects information on emerging social issues every 3 months. Several waves of the CSS contain modules on changes in relationships since the start of the pandemic in March 2020 (such as starting or ending commonlaw unions, marriages and living apart together relationships), as well as a module on changing fertility intentions due to the COVID-19 pandemic, which was first developed by the Guttmacher Institute (Lindberg et al., 2020). This module allows estimating not only whether fertility intentions changed in terms of timing of births, but also whether the intended number of children was affected, that is, whether individuals are now planning to have either fewer or more children. A question about the intended total number of children is also asked, allowing for comparisons with the same question in the 2017 General Social Survey (Family Cycle). The first wave of the CSS was conducted between April and June 2021, and the dataset is expected to be released during the fall of 2021. At a later time, the dataset will be linked with administrative data, which will allow assessing the role of policy measures such as the Canada Emergency Response Benefit (CERB) to potentially offset some of the negative labour market impacts.

Acknowledgements A previous version of this commentary was published by The Vanier Institute of the Family with the title "Uncertainty and Postponement: Pandemic Impact on Fertility in Canada." (https:// vanierinstitute.ca/uncertainty-and-postponement-pandemic-impact-on-fertility-in-canada/). Claudine Provencher (Statistics Canada) provided vital statistics data and valuable insights on observed trends in Canada.

\section{Declarations}

Disclaimer The views expressed in this article represent those of the author and are not necessarily the opinions of Statistics Canada.

\section{References}

Aassve, A., Cavalli, N., Mencarini, L., Plach, S., \& Livi Bacci, M. (2020). The COVID-19 pandemic and human fertility. Science, 369(6502), 370. https://doi.org/10.1126/science.abc9520.

Alderotti, G., Vignoli, D., Baccini, M., \& Matysiak, A. (2019). Employment uncertainty and fertility: A network meta-analysis of european research findings. Econometrics Working Papers Archive 2019_06. Universita' degli Studi di Firenze, Dipartimento di Statistica, Informatica, Applicazioni "G. Parenti"

BC Vital Statistics Agency. (2021a). Births by Local Health Area 2019. Accessed July 23, 2021 Retrieved from https://www2.gov.bc.ca/assets/gov/birth-adoption-death-marriage-and-divorce/ statistics-reports/birth-reports/births-by-lha-2019.pdf.

\footnotetext{
${ }^{6}$ https://www.statcan.gc.ca/eng/survey/household/5354
} 
BC Vital Statistics Agency. (2021b). Births by Local Health Area 2020. Accessed July 27, 2021 Retrieved from https://www2.gov.bc.ca/assets/gov/birth-adoption-death-marriage-and-divorce/ statistics-reports/birth-reports/births-by-lha-2020.pdf.

BC Vital Statistics Agency. (2021c). Births by Local Health Area 2021. Accessed July 23, 2021 Retrieved from https://www2.gov.bc.ca/assets/gov/birth-adoption-death-marriage-and-divorce/ statistics-reports/birth-reports/births-by-lha-2021.pdf

Beaujouan, É. (2020). Latest-late fertility? Decline and resurgence of late parenthood across the lowfertility countries. Population and Development Review, 0(0), 1-29. https://doi.org/10.1111/ padr. 12334.

Beaujouan, E., \& Sobotka, T. (2019). Late childbearing continues to increase in developed countries. Number 562, January 2019, Population \& Societies (INED, France)

Boberg-Fazlić, N., Ivets, M., Karlsson, M., \& Nilsson, T. (2017). Disease and fertility: Evidence from the 1918 influenza pandemic in Sweden. Discussion Paper Series. IZA - Institute of Labor Economics. IZA DP No. 10834

Cohen, P. N. (2021). Baby bust: Falling fertility in US counties is associated with COVID-19 prevalence and mobility reductions SocArXiv. https://doi.org/10.31235/osf.io/qwxz3

Comolli, C. L., \& Vignoli, D. (2021). Spreading uncertainty, shrinking birth rates: A natural experiment for Italy. European Sociological Review. https://doi.org/10.1093/esr/jcab001.

Institut de la Statistique du Québec. (2021a). Naissances, décès, accroissement naturel et mariages par MRC, Québec, 2002-2020. Accessed July 23, 2021 Retrieved from https://bdso.gouv.qc.ca/ pls/ken/ken213_afich_tabl.page_tabl?p_iden_tran=REPER05HFFQ18120546254333BmsJr\&p_ lang $=1 \& p \_m \_o=I S Q \& p \_i d \_s s \_d o m n=819 \& p \_i d \_r a p r t=1859 \#$ tri_phe $=5 \&$ tri_ra $=00 \& \operatorname{tri} \mathrm{mrc}=$ AAA.

Institut de la Statistique du Québec. (2021b). Taux de fécondité selon le groupe d'âge de la mère, indice synthétique de fécondité et âge moyen à la maternité, Québec. Accessed July 23, 2021 Retrieved from https://bdso.gouv.qc.ca/pls/ken/ken213_afich_tabl.page_tabl?p_iden_tran= REPER05HFFQ18120546254333BmsJr\&p_lang=1\&p_m_o=ISQ\&p_id_ss_domn=819\&p_id_ raprt $=785$.

Kluesener, S., \& Lerch, M. (2020). Fertility and economic crisis: How does early 20th century compare to early 21st century? Paper presented at the Population Association of America Annual Meeting.

Kluessener, S., \& Lerch, M. (2020). Fertility and economic crisis: How does early twentieth century compare to early twenty-first century? Paper presented at the Population Association of America, Virtual.

Lappegård, T., Dommermuth, L., Kristensen, A. P., Vignoli, D., \& Minelli, A. (2020). Fertility intentions and economic uncertainty in Norway: Which uncertainty matters?. Population Association of America Annual Meeting. Padova, Italy

Lappegård, T., Kristensen, A. P., Dommermuth, L., Vignoli, D., \& Minelli, A. (2021). Economic uncertainty and couples' fertility intentions in Italy and Norway. Paper presented at the Population Association of America Annual Meeting, Virtual.

Lindberg, L. D., VandeVusse, A., Mueller, J., \& Kirstein, M. (2020). Early impacts of the COVID-19 pandemic: Findings from the 2020 Guttmacher Survey of reproductive health experiences. Lindberg LD et al., Early Impacts of the COVID-19 Pandemic: Findings from the 2020 Guttmacher Survey of Reproductive Health Experiences, New York: Guttmacher Institute, 2020, https:// www.guttmacher.org/report/early-impacts-covid-19-pandemic-findings-2020-guttmacher-surveyreproductive-health. Accessed November 20, 2020

Luppi, F., Arpino, B., \& Rosina, A. (2020). The impact of COVID-19 on fertility plans in Italy, Germany, France, Spain, and the United Kingdom. Demographic Research, 43(47), 1399-1412.

Marshall, J., Burd, C., \& Burrows, M. (2021). Working from home during the pandemic. Accessed August 4, 2021 Retrieved from https://www.census.gov/library/stories/2021/03/working-fromhome-during-the-pandemic.html.

Marteleto, L. J., Guedes, G., Coutinho, R. Z., \& Weitzman, A. (2020). Live births and fertility amid the Zika epidemic in Brazil. Demography. https://doi.org/10.1007/s13524-020-00871-x.

Matysiak, A., Sobotka, T., \& Vignoli, D. (2020). The great recession and fertility in Europe: A subnational analysis. European Journal of Population. https://doi.org/10.1007/s10680-020-09556-y.

Sobotka, T., Jasilioniene, A., Galarza, A., Zeman, K., Nemeth, L., and Jdanov, D. (2021). Baby bust in the wake of the COVID-19 pandemic? First results from the new STFF data series. Preprint 
- March 2021 Retrieved from https://www.researchgate.net/publication/350368881, https://doi. org/10.31235/osf.io/mvy62

Sobotka, T., Skirbekk, V., \& Philipov, D. (2011). Economic recession and fertility in the developed world. Population and Development Review, 37(2), 267-306.

Statistics Canada. (2020a). Births, 2019. Accessed July 28 , 2021 Retrieved from https://www 150. statcan.gc.ca/n1/daily-quotidien/200929/dq200929e-eng.htm.

Statistics Canada. (2020b). Labour Force Survey, May 2020 (11-001-X). Accessed July 27, 2021 Retrieved from https://www150.statcan.gc.ca/n1/daily-quotidien/200605/dq200605a-eng.htm.

Statistics Canada. (2021a). Estimates of the components of natural increase, quarterly (Table: 17-10-0059-01 (formerly CANSIM 053-0001)). Accessed July 27, 2021 Retrieved from https:// www150.statcan.gc.ca/t1/tbl1/en/tv.action?pid=1710005901.

Statistics Canada. (2021b). Labour Force Survey, June 2021. Accessed August 6, 2021 Retrieved from https://www150.statcan.gc.ca/n1/en/daily-quotidien/210709/dq210709a-eng.pdf?st=_evhSvQg.

Statistics Canada. (2021c). Working from home during the COVID-19 pandemic, April 2020 to June 2021. Accessed August 9, 2021 Retrieved from https://www150.statcan.gc.ca/n1/daily-quoti dien/210804/dq210804b-eng.htm.

Vignoli, D., Bazzani, G., Guetto, R., Minello, A., \& Pirani, E. (2020). Uncertainty and narratives of the future: A theoretical framework for contemporary fertility. In R. Schoen (Ed.), Analyzing contemporary fertility (Vol. 51, pp. 25-47). Springer.

Publisher's Note Springer Nature remains neutral with regard to jurisdictional claims in published maps and institutional affiliations. 